\title{
Taste Preference for Fatty Acids Is Mediated by GPR40 and GPR120
}

\author{
Cristina Cartoni, ${ }^{1 \star}$ Keiko Yasumatsu, ${ }^{2 \star}$ Tadahiro Ohkuri, ${ }^{2}$ Noriatsu Shigemura, ${ }^{2}$ Ryusuke Yoshida, ${ }^{2}$ Nicolas Godinot, ${ }^{1}$ \\ Johannes le Coutre, ${ }^{1}$ Yuzo Ninomiya, ${ }^{2}$ and Sami Damak ${ }^{1}$ \\ ${ }^{1}$ Nestlé Research Center, Lausanne 1000, Switzerland, and ${ }^{2}$ Section of Oral Neuroscience, Graduate School of Dental Sciences, Kyushu University, Fukuoka \\ 812-8582, Japan
}

The oral perception of fat has traditionally been considered to rely mainly on texture and olfaction, but recent findings suggest that taste may also play a role in the detection of long chain fatty acids. The two G-protein coupled receptors GPR40 (Ffar1) and GPR120 are activated by medium and long chain fatty acids. Here we show that GPR120 and GPR 40 are expressed in the taste buds, mainly in type II and type I cells, respectively. Compared with wild-type mice, male and female GPR120 knock-out and GPR40 knock-out mice show a diminished preference for linoleic acid and oleic acid, and diminished taste nerve responses to several fatty acids. These results show that GPR40 and GPR120 mediate the taste of fatty acids.

\section{Introduction}

The sense of taste comprises five main qualities, sweet, bitter, sour, salty and umami. There is mounting evidence that oral fat also activates the gustatory system, in addition to the trigeminal and olfactory systems. In short access tests, anosmic and intact rodents prefer oils to xantham gum, which mimics the texture of oil (Takeda et al., 2001; Fukuwatari et al., 2003), and humans can taste long chain free fatty acids even when olfaction is eliminated by using a nose clip and the specific texture of fatty acids is masked by diluting them in viscous solutions (Chale-Rush et al., 2007). Gustatory nerve transection impairs fatty acid detection and/or preference in rats and mice (Stratford et al., 2006; Pittman et al., 2007).

Triglycerides, the main components of oils and of fatty food, are hydrolyzed in the tongue by a lingual lipase secreted from the von Ebner gland and the released free fatty acids are detected by the taste system (Gilbertson et al., 1997; Kawai and Fushiki, 2003).

The current knowledge on possible transduction mechanisms of fat taste is limited. Delayed rectifying $\mathrm{K}^{+}$(DRK) channels are inhibited by polyunsaturated fatty acids in taste bud cells (Gilbertson et al., 1997). Knock-out mice lacking CD36, a fatty acid transporter expressed in several tissues including the taste buds have a diminished preference for linoleic acid and soybean oil (Laugerette et al., 2005; Sclafani et al., 2007a).

Received Jan. 29, 2010; revised April 28, 2010; accepted May 1, 2010.

This work was supported by internal research funds from Nestec, and Grants-in-Aid 18109013, 18077004 (Y.N.) for Scientific Research from the Japan Society for the Promotion of Science. We thank Chrystel Loret for advice on the measurement of viscosity and Muriel Briand for technical assistance.

${ }^{*}$ C.C. and K.Y. contributed equally to this work.

Correspondence should be addressed to either of the following: Sami Damak, Nestlé Research Center, Vers-chezles-Blanc, Lausanne 1000, Switzerland, E-mail:sami.damak@rdls.nestle.com; or Yuzo Ninomiya, Oral Neuroscience, Graduate School of Dental Sciences, Kyushu University, Fukuoka 812-8582, Japan, E-mail: yuninom@dent.kyushu-u.ac.jp.

DOI:10.1523/JNEUROSCI.0496-10.2010

Copyright $\odot 2010$ the authors $\quad 0270-6474 / 10 / 308376-07 \$ 15.00 / 0$
Both DRK channels and CD36 appear to play an important role in the detection of fatty acids by the gustatory system but whether direct interaction of fatty acids with any of these molecules is the initiating event in the fat taste signaling cascade remains to be elucidated.

For sweet, bitter and umami, the taste sensation is initiated by tastants binding to G-protein coupled receptors (for review see Lindemann, 2001). GPR40 and GPR120 are G-protein coupled receptors, which respond to medium and long chain fatty acids in vitro (Briscoe et al., 2003; Itoh et al., 2003; Kotarsky et al., 2003; Hirasawa et al., 2005). To determine the role of these receptors in the detection of fat by the taste receptor cells, we investigated their expression in the taste buds of mice and compared the preference and taste nerve responses to fatty acids of wild-type, GPR120 and GPR40 knock-out mice.

\section{Materials and Methods}

Animals. The TrpGFP mice were made with a construct containing, $5^{\prime}$ to $3^{\prime}, 11 \mathrm{~kb}$ of mouse Trpm5 5' flanking region, the coding region of enhanced green fluorescent protein (eGFP), an internal ribosome entry site (IRES) and a truncated human CD4 gene to be used in other studies as a surface marker of the cells that express the transgene. These mice were produced in a C57BL/6J $\times$ BALB/c background and were subsequently backcrossed for 5 generations to wild-type C57BL/6J mice.

The GPR40 knock-out mice were purchased from Deltagen. These mice contain a deletion in the GPR40 gene sequence extending from nucleotide 143 to nucleotide 284 after the transcription start site and a neocassette inserted at the site of the deleted sequence. This deletion removes most of transmembrane helices 2 and 3, and introduces stop codons downstream from the insertion site. The mice were created in $129 /$ Svj $\times 129 /$ SV-CP background and were crossed with wild-type $\mathrm{C} 57 \mathrm{BL} / 6 \mathrm{~N}$ mice then intercrossed to produce wild-type $\left(\mathrm{GPR} 40^{+/+}\right)$, heterozygous $\left(\mathrm{GPR} 40^{+/-}\right.$) and knock-out $\left(\mathrm{GPR} 40^{-/-}\right)$mice. Genotyping was done by real-time PCR of tail biopsy DNA.

The GPR120 KO mice contain a deletion in the GPR120 gene extending from nucleotide -5870 ( $5870 \mathrm{nt}$ upstream from the ATG) to nucleotide 768 downstream from the ATG (supplemental Fig. S1, available at www.jneurosci.org as supplemental material). This deletion removes the 
A
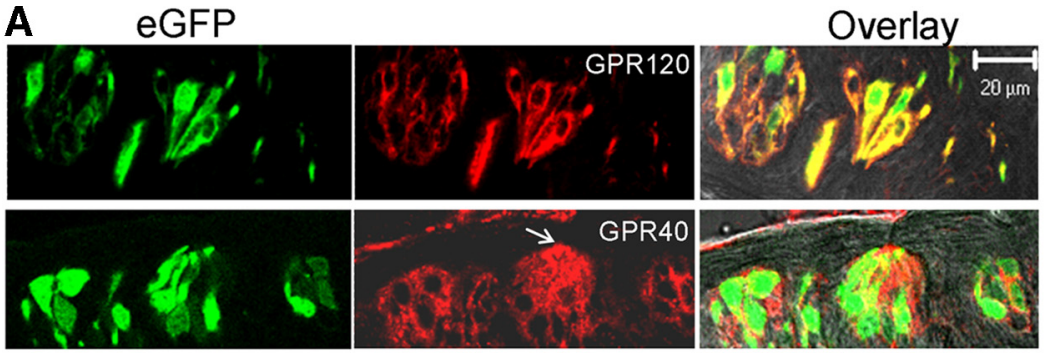

B

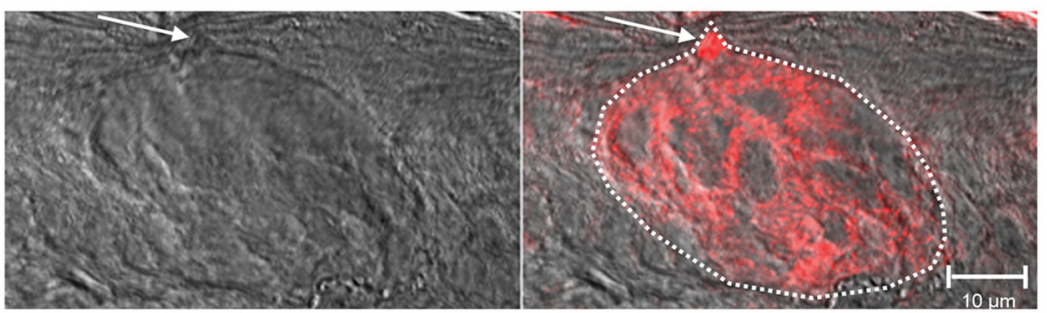

C
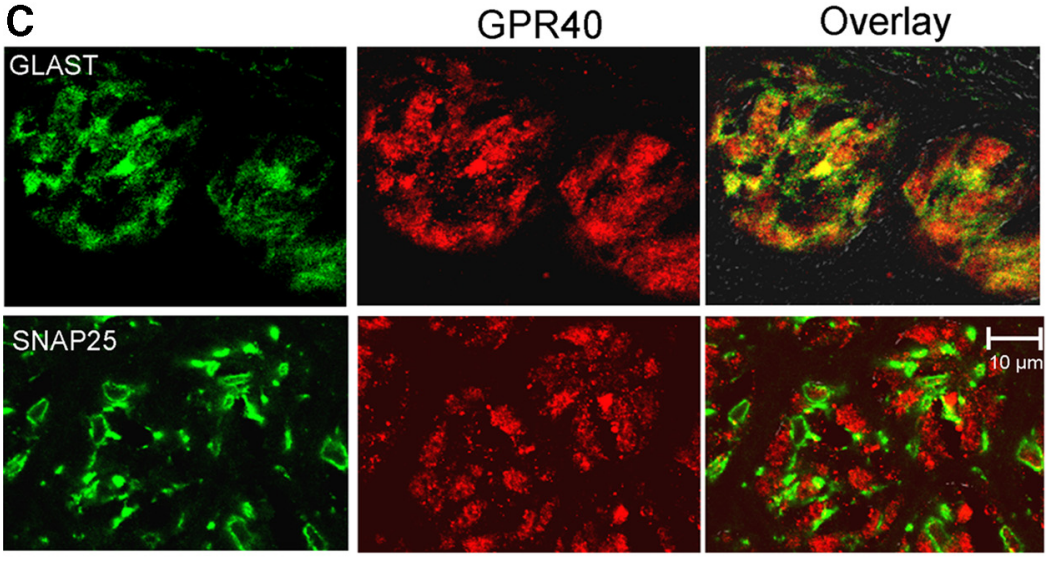

D
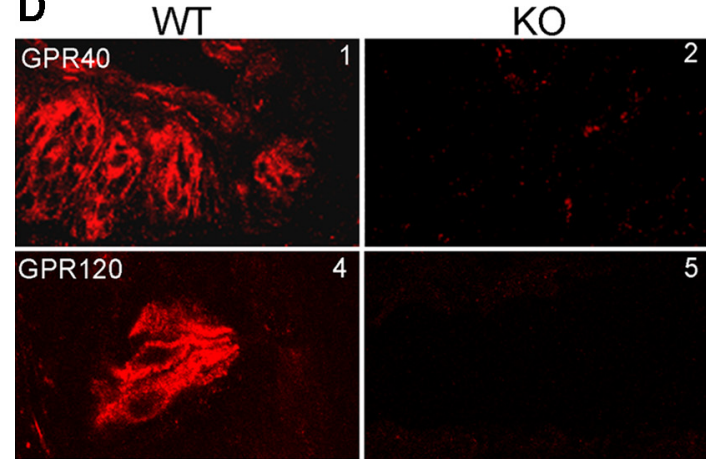

$\mathrm{KO}$, Gustducin stain
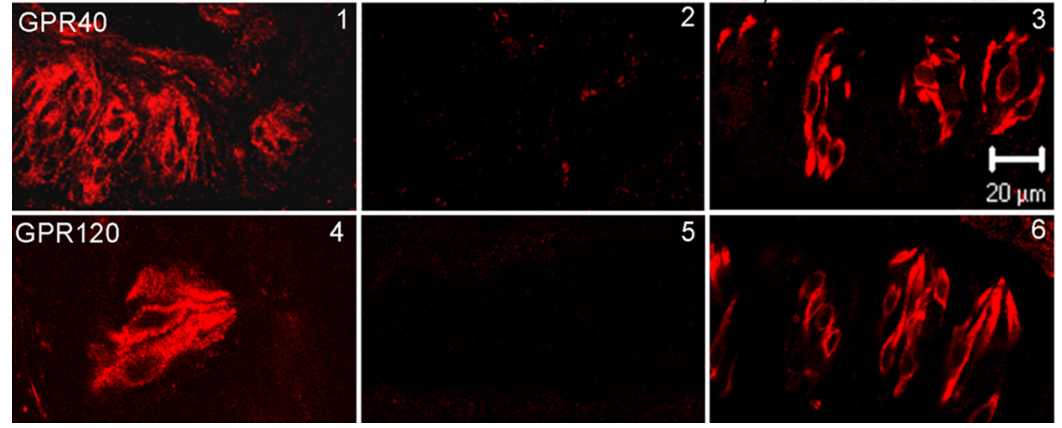

Figure 1. A, Photomicrographs of frozen sections of circumvallate papilla from transgenic mice expressing eGFP under the control of the Trpm5 promoter stained (red) with GPR120 (top) or GPR40 antibodies (bottom). The staining obtained with the GPR120 antibody is mostly colocalized with Trpm5 promoter-driven eGFP fluorescence. The GPR40 antibody stained mainly cells that do not express eGFP. With this antibody, staining is most intense in the taste pore (arrow). $B$, Microphotograph of a frozen section of foliate papilla from a wild-type mouse stained with a GPR40 antibody. Staining is most intense in the taste pore (arrow). The dotted line shows the boundary of the taste bud. C, Photomicrographs of frozen sections of circumvallate papilla from wild-type mice double-stained with GPR40 antibody (red) and GLAST (top, green) or SNAP25 (bottom, green) antibodies; Most GPR40-expressing cells also express GLAST and there is little coexpression of SNAP25 and GPR40. D, Photomicrographs of frozen sections of circumvallate papillae from wild-type $(1,4), G P R 40$ KO $(2,3)$ and GPR120 KO $(5,6)$ mice stained with GPR40 $(1,2), \operatorname{GPR} 120(4,5)$, or $\alpha$-gustducin $(3,6)$ specific antibodies. The GPR120 and GPR40 proteins are not detected in the CV of GPR120 K0 and GPR40 K0 mice, respectively. Sections from GPR120 K0 or GPR40 K0 mice stained with $\alpha$-gustducin antibody show that the knock-out mice have normal taste buds and type II cells, and that the expression of $\alpha$-gustducin is not affected by the absence of GPR120 or GPR40. promoter region, the transcription and translation start sites and exon 1 , which contains the $\mathrm{N}$-terminal region and the first four transmembrane regions. The mice were created in C57BL/6J background and were maintained in this background.

Immunohistochemistry. The antibodies used are a rabbit antiserum raised against a synthetic peptide corresponding to the third extracellular loop of human GPR40 with $84 \%$ identity with mouse GPR40 used at 1:70 dilution (Novus Biologicals); a rabbit antiserum raised against a synthetic peptide corresponding to the fifth transmembrane domain of human GPR120, with 94\% identity with mouse GPR120 used at 1:1000 dilution (LifeSpan Biosciences); a goat antiserum raised against a peptide mapping at the $\mathrm{N}$ terminus of human GLAST used at 1/50 dilution (Santa Cruz Biotechnology); a goat polyclonal antiserum raised against a synthetic peptide mapping at the $\mathrm{C}$ terminus of human SNAP25 used at 1:2000 dilution (Santa Cruz Biotechnology); a rabbit antiserum raised against a peptide mapping within a highly divergent domain of rat $\alpha$-gustducin used at 1/500 dilution (Santa Cruz Biotechnology).

Tongues from wild-type, GPR40 KO, GPR120 KO or TrpGFP transgenic mice were fixed for $1.5 \mathrm{~h}$ in $4 \%$ paraformaldehyde, then incubated overnight in $20 \%$ sucrose. Circumvallate, foliate and fungiform papillae were dissected under the microscope, embedded in OCT compound (Tissue-Tek, Sakura) and frozen in dry ice. Cryostat sections $(12 \mu \mathrm{m})$ were washed in $1 \times$ PBS and blocked in $2 \%$ donkey serum, $0.19 \%$ BSA and $0.003 \%$ Triton X-100 in PBS for $30 \mathrm{~min}$ at room temperature. Blocked sections were incubated overnight at $4{ }^{\circ} \mathrm{C}$ with the primary antibody diluted in blocking solution. After washing, the sections were incubated at room temperature for $30 \mathrm{~min}$ in Alexa Fluor 555 anti-rabbit IgG (Invitrogen) or Alexa Fluor 488 anti-goat secondary antibodies diluted $1 / 500$.

Sections were then mounted in Vectashield medium (Vector Laboratories) and analyzed under a confocal microscope (Zeiss).

Two-bottle preference tests. Two-bottle preference tests were conducted as previously described (Wong et al., 1996), comparing GRP $40^{+/-}$and GPR40 KO littermates, $n=10$, males and females, or comparing GPR120 KO and GPR $120^{+/+}$littermates, $n=15$, males and females. Briefly, mice were individually housed, provided with food ad libitum and presented with two sipper bottles for $48 \mathrm{~h}$. One bottle contained vehicle only and the other the tastant to be tested. The bottles were switched after $24 \mathrm{~h}$ to account for position effects. The tastants were presented at increasing concentrations. Between different compounds the mice were allowed 1 week of rest during which they were presented with water. The fatty acids were suspended in $0.3 \%$ xanthan gum, then sonicated to make stable suspensions. The control bottle contained $0.3 \%$ xanthan gum. The intake volumes and the ratios of tastant to total liquid consumed were recorded. For statistical 
analysis, the preference ratios for all concentrations were analyzed with the general linear model repeated measures of the statistics program SPSS with tastant concentration as a within-subject factor and genotype as a between-subject factor. A $p$ value $<0.05$ was considered significant.

Brief access test. The brief access tests were conducted using a Davis MS-160 mouse gustometer (DiLog Instruments) comparing in experiment 1 GPR40 KO and wild-type mice ( $n=10$ and 9, respectively), and in experiment 2 comparing GPR120 KO and wild-type mice ( $n=13$ and 11, respectively). The mice were tested in $30 \mathrm{~min}$ sessions in which one tastant solution or vehicle alone are presented alternatively. When the mouse starts drinking each lick closes an undetectable electric circuit and the number of licks is recorded by a computer. A trial is initiated when the mouse starts licking, and lasts $5 \mathrm{~s}$, then the other bottle is presented. The average number of licks per trial is measured for each mouse. The two concentrations were given at different testing sessions, with $1 \mathrm{~d}$ rest in between. On the day before the test the mice were given $2 \mathrm{ml}$ of water and $1 \mathrm{~g}$ of food to give them an incentive to drink and seek calorie-rich solutions during the test session. After the session, the mice were allowed $24 \mathrm{~h}$ of food and water ad libitum before being food and water restricted and tested again. Linoleic acid was tested at 100 and $350 \mathrm{~mm}$ in $0.2 \%$ xanthan gum. The control solution was $0.2 \%$ xanthan gum. The data were analyzed by paired $\mathrm{T}$ tests comparing the average number of licks per trial for tastant versus vehicle alone. The Bonferroni correction was applied to account for multiple comparisons (two concentrations).

Measurement of viscosity. Viscosity flow curves (viscosity versus shear rate) were obtained using a RheoStress RS100 (Haake Meßtechnick $\mathrm{GmbH}$ ) with a double gap geometry. Measurements were made in the shear rate range $0.1-100 \mathrm{~s}^{-1}$ at room temperature. The values shown in supplemental Table S1, available at www.jneurosci.org as supplemental material are for a shear rate of $50 \mathrm{~s}^{-1}$.

Nerve recordings. Mice were anesthetized with an intraperitoneal injection of sodium pentobarbital and maintained at a surgical level of anesthesia with additional injections of sodium pentobarbital. Recordings were obtained from the right chorda tympani (CT) and glossopharyngeal (GL) nerves from different mice. Neural responses induced by chemical stimulation of the tongue were fed into an amplifier (Iyodenshikogaku K-1). Whole nerve responses were integrated with a time constant of $1.0 \mathrm{~s}$ and recorded on a computer for later analysis using PowerLab system (PowerLab/sp4; ADInstruments). (For more details, see Ninomiya, 1998; Kawai et al., 2000.)

The solutions used to stimulate the tongue are oleic acid, linolenic acid, docosahexaenoic acid (DHA) $1 \mathrm{~mm}, 3 \mathrm{~mm}, 10 \mathrm{~mm}$ each, lauric acid and linoleic acid $1 \mathrm{~mm}, 3 \mathrm{~mm}, 10 \mathrm{~mm}, 30 \mathrm{~mm}, 100 \mathrm{~mm}$ each, $0.1 \%$, $0.3 \%$ and $1 \%$ Ultralec, a mix of phosphatidyl choline, phosphatidyl ethanolamine and phosphatidyl inositol, $0.1 \%, 0.3 \%, 1 \%$ mineral oil, $0.1 \mathrm{~mm}, 1 \mathrm{~mm}, 10 \mathrm{~mm}, 20 \mathrm{~mm}, 50 \mathrm{~mm}$ denatonium benzoate with or without $55 \mu \mathrm{M}$ linoleic acid and $33 \mu \mathrm{M}$ oleic acid, $10 \mathrm{~mm}, 30 \mathrm{~mm}, 100$ $\mathrm{mm}, 300 \mathrm{~mm}, 1 \mathrm{~m} \mathrm{NaCl}, 1 \mathrm{~mm}, 3 \mathrm{~mm}, 10 \mathrm{~mm} \mathrm{HCl}, 10 \mathrm{~mm}, 30 \mathrm{~mm}, 100$ $\mathrm{mm}, 300 \mathrm{~mm}, 1 \mathrm{~m}$ monopotassium glutamate, $10 \mathrm{~mm}, 30 \mathrm{~mm}, 100 \mathrm{~mm}$, $300 \mathrm{~mm}, 500 \mathrm{~mm}, 1 \mathrm{~m}$ sucrose and $3 \%, 5 \%$ and $8 \%$ ethanol. Lauric acid was first dissolved in warm EtOH, and diluted to its highest concentration in distilled water. The final concentrations of EtOH was $8 \%$. Lower concentrations of these fatty acids were obtained from dilution of the highest concentration with distilled water and thereby have lower final concentrations of EtOH. All other compounds were dissolved and suspended in distilled water with sonication. The compounds were applied to the tongue for $1 \mathrm{~min}$ for the CT or $2 \mathrm{~min}$ for the GL, followed by rinse with distilled water.

In the data analysis for whole-nerve responses, the magnitude of the integrated neural activities at 6 different time points for $1 \mathrm{~min}$ after stimulus (at 5, 15, 25, 35, 45, $55 \mathrm{~s}$ ) for the CT and for $2 \mathrm{~min}$ (at 10, 30, 50, 70,90 , and $110 \mathrm{~s}$ ) for the GL was measured and averaged. Relative response magnitudes (averaged) for each test stimulus were normalized to the response magnitude to $0.1 \mathrm{M} \mathrm{NH}_{4} \mathrm{Cl}$. The nerve responses were compared between groups by repeated-measures ANOVA with a degree of significance chosen at $<0.05$.
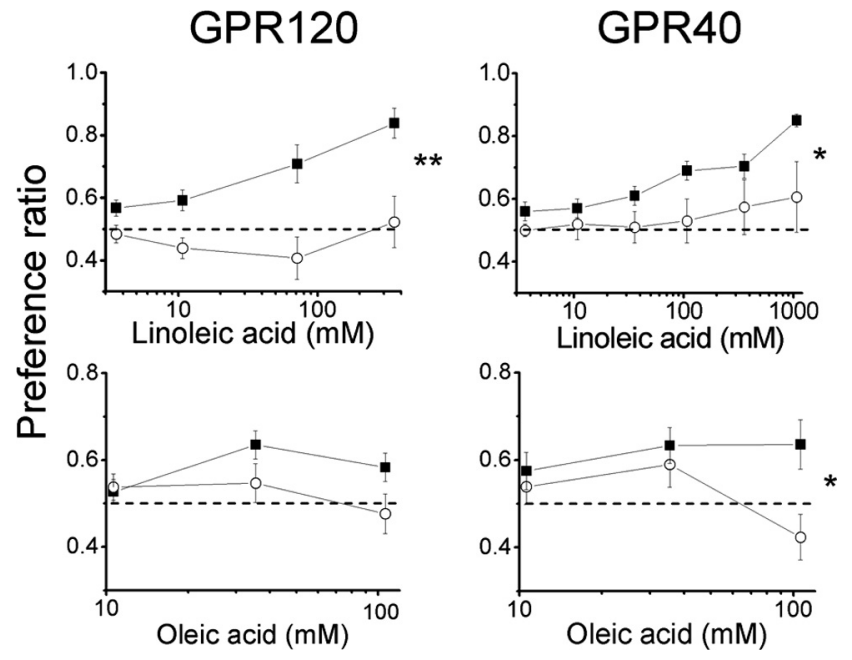

Figure 2. Mean preference ratios for tastants consumed during $48 \mathrm{~h}$ two-bottle preference tests comparing $\mathrm{KO}$ (open circles) and control mice (black squares). The mice were given two bottles, one with tastant and one with vehicle alone for $24 \mathrm{~h}$ then the bottles were swapped to eliminate position preferences and presented for an extra $24 \mathrm{~h}$. The vehicle was $0.3 \%$ xanthan gum to mimic the viscosity of the fatty suspensions. The ratios of tastant to total liquid consumed over $48 \mathrm{~h}$ were measured and compared between groups. The GPR40 K0 mice showed a diminished preference for linoleic acid and oleic acid. The GPR120 KO mice showed a diminished preference for linoleic acid. The dashed line indicates the indifference line. Asterisks indicate a significant difference in preference $\left({ }^{*} p<0.05\right)$ when all concentrations are analyzed together; ${ }^{* *} p<0.001 . n=10-15$; error bars are SEM.

$100 \mathrm{mM}$ linoleic acid

350mM linoleic acid
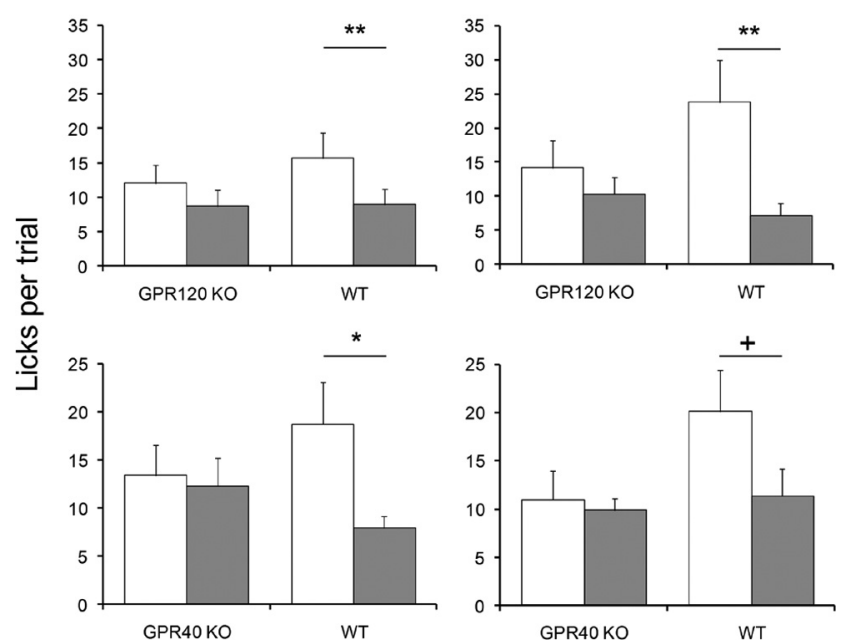

Figure 3. Mean number of licks per trial during short access tests comparing linoleic acid ( 100 or $350 \mathrm{~mm}$, open bars) and xanthan gum (gray bars). GPR40 K0, GPR120 K0 and wild-type mice were tested. The mice were water and food restricted $23.5 \mathrm{~h}$ before the testing session, and then tested for $30 \mathrm{~min}$ in $5 \mathrm{~s}$ trials with one concentration of tastant and vehicle presented alternatively. The mean number of licks per $5 \mathrm{~s}$ trial was recorded. ${ }^{+} p=0.027,{ }^{*} p<0.025$, ${ }^{* *} p<0.01$. Error bars are SEM.

\section{Results}

\section{Immunohistochemistry}

We used sections from wild-type and TrpGFP transgenic mice (Bezençon et al., 2006). In these transgenic mice, expression of enhanced green fluorescent protein (eGFP) is driven by the Trpm5 promoter and therefore marks all the cells expressing Trpm5, the type II taste cells, which include the bitter, sweet and umami-responsive taste receptor cells (Zhang et al., 2003). 

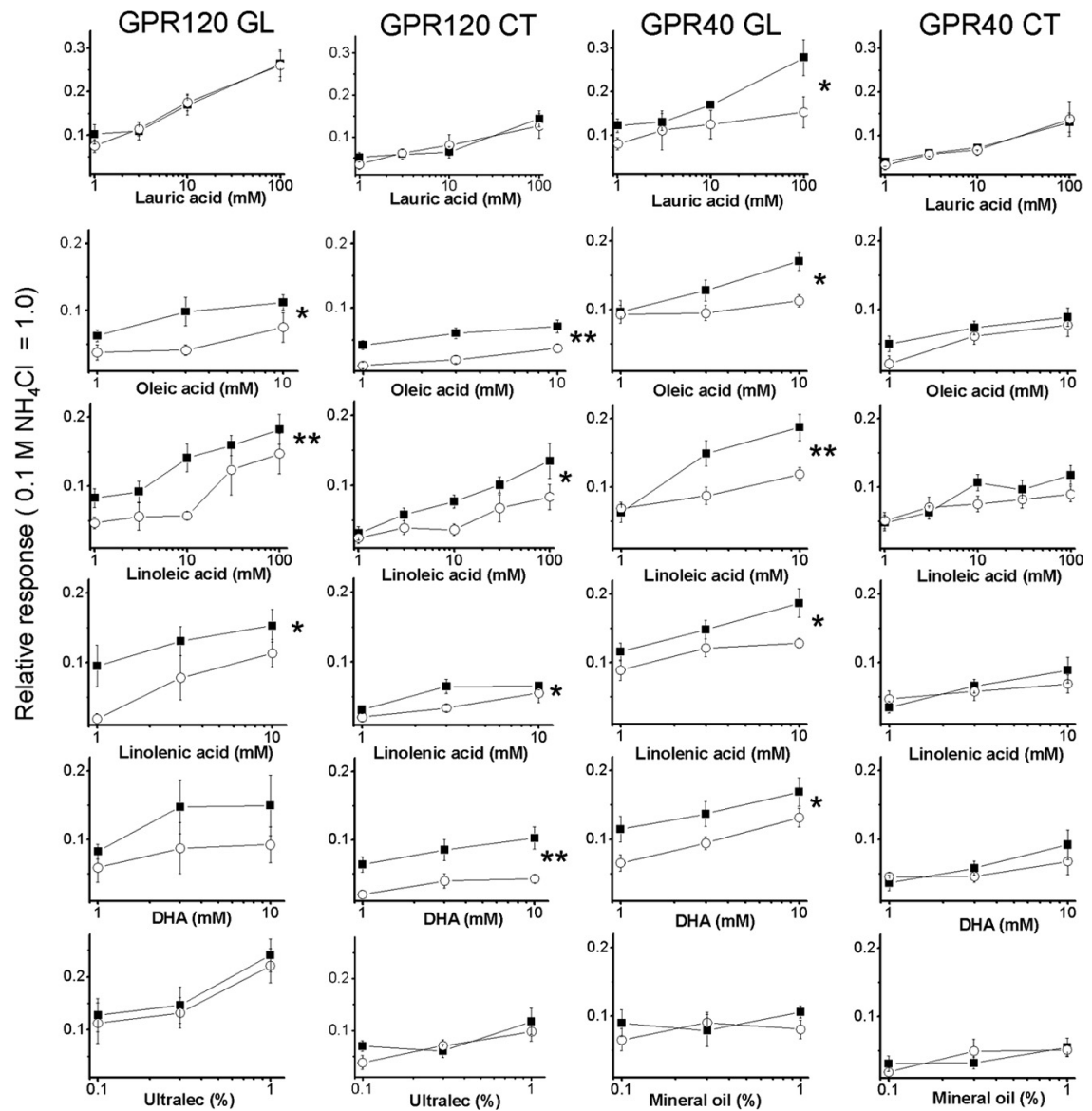

Figure 4. CT and GL integrated whole nerve responses of control (black squares) and GPR120 K0 or GPR40 K0 (open circles) mice to lingual application of tastants. All responses were normalized to the response to $100 \mathrm{mM} \mathrm{NH}_{4} \mathrm{Cl}$. GPR120 KO mice show diminished responses in both nerves to several fatty acids, whereas only the response of the GL nerve is affected in the GPR40 KO mice. The response to lauric acid is diminished in the GPR40 KO, but not in the GPR120 KO mice. There is no effect of mineral oil. Asterisks indicate a significant difference between $\mathrm{K} 0$ and control, across all concentrations $\left({ }^{*} p<0.05\right.$ and ${ }^{* *} p<0.01$, respectively). For each group and each nerve, $n=6-9$. Error bars are SEM.

Immunohistochemistry of circumvallate papillae (CV) sections with GPR40 and GPR120-specific antibodies showed staining of a subset of taste cells with each antibody (Fig. 1A). In addition to the $\mathrm{CV}$, GPR120 is expressed in the foliate and fungiform papillae (data not shown) and GPR40 is expressed in foliate papillae (Fig. $1 B)$, but only in a small number of fungiform papillae (2.5\% of all fungiform papillae examined express this receptor (data not shown)). Interestingly, the immunostaining is strongest at the taste pore (Fig. $1 A, B$, arrows), indicating that GPR40 is at a location where it can interact with molecules in the oral cavity. The GPR40 immunostain in the body of the taste cells appears weak and granular, suggesting that it may correspond to the trafficking protein. The GPR120 antibody showed $\sim 90 \%$ coexpression of GPR120 and eGFP (Fig. 1A) consistent with findings by others (Matsumura et al., 2009). Immunostaining of CV sections from TrpGFP mice and double immunostaining suggested a large degree of coexpression in taste cells of GPR40 and glial glutamate/aspartate transporter (GLAST), a marker of type I cells (Lawton et al., 2000), and $\sim 20 \%$ coexpression of GPR40 with Trpm5-driven eGFP a marker of type II cells or with synaptosomal-associated protein of $25 \mathrm{kDa}$ (SNAP25), a marker of type III cells (Yang et al., 2000) (Fig. 1C).

\section{Behavioral tests in $\mathrm{KO}$ mice}

To determine the role of GPR40 and GPR120 in taste signal transduction in vivo, we used mice in which GPR40 or GPR 120

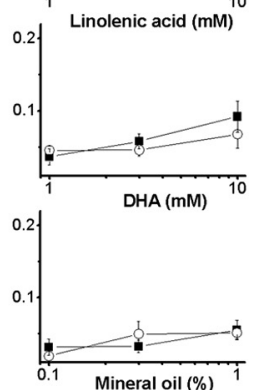

were knocked out by homologous recombination in embryonic stem (ES) cells. Immunohistochemistry showed no immunostaining of taste tissue from GPR40 KO or GPR120 KO mice with GPR40 or GPR120-specific antibodies, respectively, demonstrating that GPR40 KO and GPR120 KO mice lack the GPR40 and GPR120 proteins, respectively (Fig. $1 D$ ). Knocking out GPR40 or GPR120 did not alter the architecture of the taste buds, or the pattern of expression of $\alpha$-gustducin, a gene expressed in type II taste cells (Fig. 1D).

Behaval tests were performed to determine the response of GPR40 KO and GPR120 KO mice to tastants. Free fatty acids were suspended in $0.3 \%$ xanthan gum to mask their viscosity and sonicated to stabilize the suspension. The viscosities of suspensions of up to $350 \mathrm{~mm}$ fatty acid are not substantially different from those of $0.3 \%$ xanthan gum, whereas a $1 \mathrm{~m}$ suspension is $\sim 2 \times$ as viscous (supplemental Table S1, available at www.jneurosci.org as supplemental material). In $48 \mathrm{~h}$ two bottle preference tests, overall analysis of all concentrations for a given compound showed a diminished preference for linoleic acid and oleic acid in GPR40 $\mathrm{KO}(p<$ $0.05)$ and for linoleic acid in GPR120 KO mice $(p<0.001)$ compared with control animals (Fig. 2, supplemental Table S3, available at www.jneurosci.org as supplemental material). Mice from both knock-out lines were indifferent to all concentrations of linoleic acid and oleic acid, suggesting that knocking out either GPR 40 or GPR120 has a profound effect on the ability of mice to detect those fatty acids.

We also performed short access tests using a lickometer where the mice are exposed to tastants for $30 \mathrm{~min}$ and their licking responses measured in trials lasting $5 \mathrm{~s}$ each. During this short period of time and with very little tastant ingested, postingestive cues do not contribute to the response to tastants. Wild-type mice performed significantly more licks per trial with 100 or $350 \mathrm{~mm}$ linoleic acid than with $0.2 \%$ xanthan gum $(p<0.025)$ showing preference for this fatty acid. GPR40KO and GPR120 KO did not show any significant difference in licks per trial comparing linoleic acid and vehicle, thereby showing indifference to this tastant (Fig. 3). These data show that the reduced preference for fatty acids in $\mathrm{KO}$ animals is accounted for mainly by a peripheral mechanism and not by postingestive cues.

\section{Nerve recordings}

To determine whether GPR40 and GPR120 are involved in the detection of fat by the gustatory system, we recorded whole nerve responses of the mouse taste nerves (Ninomiya, 1998; Kawai et al., 2000) to fatty acids (Fig. 4; supplemental Tables S4, S5, supplemental Fig. S2, available at www.jneurosci.org as supplemental material). The magnitude of the taste nerve responses to fatty acids was small, but significantly different from baseline (supplemental Table S5, available at www.jneurosci.org as supplemental 
material). The responses of the chorda tympani (CT), which innervates the front of the tongue, are smaller than those of the glossopharyngeal nerve (GL), which innervates the back of the tongue. The GL responses of GPR40 KO mice and GPR120 KO mice to oleic acid, linoleic acid, and linolenic acid are weaker than those of control mice $(p<0.05$ for oleic acid and linolenic acid, $p<0.01$ for linoleic acid). For DHA, the GL response of the GPR40 KO mice was diminished compared with WT animals $(p<0.05)$ whereas with the GPR120 KO mice the decrease was not significant. For lauric acid, there was a decrease in the response of the GPR40 KO mice $(p<0.05)$ but not in that of GPR120 knock-outs. Importantly, this is consistent with data from cultured cells which showed that GPR40 responds to lauric acid whereas GPR120 does not (Briscoe et al., 2003; Itoh et al., 2003; Kotarsky et al., 2003; Hirasawa et al., 2005). No difference was observed between the responses of GPR120 KO and WT mice to Ultralec, a mix of phosphatidyl choline, phosphatidyl ethanolamine and phosphatidyl inositol, suggesting that GPR120 does not play a role in the taste response to phospholipids. No GL response to mineral oil from GPR $120 \mathrm{KO}$, GPR40 KO and control mice was obtained, indicating that the recorded GL response to fatty acids is not caused by tactile cues. The responses of the CT to oleic acid, linoleic acid, linolenic acid and DHA are diminished in the GPR120 KO compared with WT mice ( $p<0.05$ for linoleic acid and linolenic acid, $p<0.01$ for oleic acid and DHA), but no difference was observed between GPR40 KO and WT animals. These data are consistent with our immunohistochemistry findings that GPR120 but not GPR40 is expressed in the fungiform papillae, which are innervated by the CT.

\section{Modulation of bitter taste by fatty acids}

Fat also alters other taste modalities (Pittman et al., 2006). To determine whether this modulation occurs via GPR40 and/or GPR120, we performed nerve recording studies using denatonium benzoate, with or without addition of $88 \mu \mathrm{M}$ linoleic and oleic acid using wild-type, GPR120 KO and GPR40 KO mice. When the fatty acid mix was added to denatonium benzoate, the taste nerve responses to the mixture were decreased compared with denatonium alone ( $p<0.01$ for CT response, $p<0.001$ for GL response) but this decrease was identical in GPR40 KO, GPR120 KO and control mice (Fig. 5). These data show that GPR40 and GPR120 do not mediate the reduction in response to bitter compounds by the linoleic/oleic acid mixture.

\section{GPR40 and GPR120 do not affect other taste modalities}

No difference between the responses of knock-outs and control mice was observed for denatonium benzoate (bitter), sucrose (sweet), hydrochloric acid (sour), sodium chloride (salty), and monopotassium glutamate (umami) (Figs. 5, 6; supplemental Fig. S3, available at www.jneurosci.org as supplemental material), indicating that the reduced behavioral and electrophysiological taste responses of the GPR40 KO and GPR120 KO mice are specific for fatty acids.

\section{Discussion}

There is mounting evidence that the gustatory system contributes to the detection of fat and the signaling pathways involved are beginning to be unraveled. Based on immunohistochemical, behavioral and electrophysiological evidence, our data show that both GPR120 and GPR40 play an essential role in the mouse taste response to fatty acids. GPR40 appears to be active mainly at the back of the tongue because GPR40 immunoreactivity was found in the $\mathrm{CV}$ and the foliate, but rarely in the fungiform papillae, and

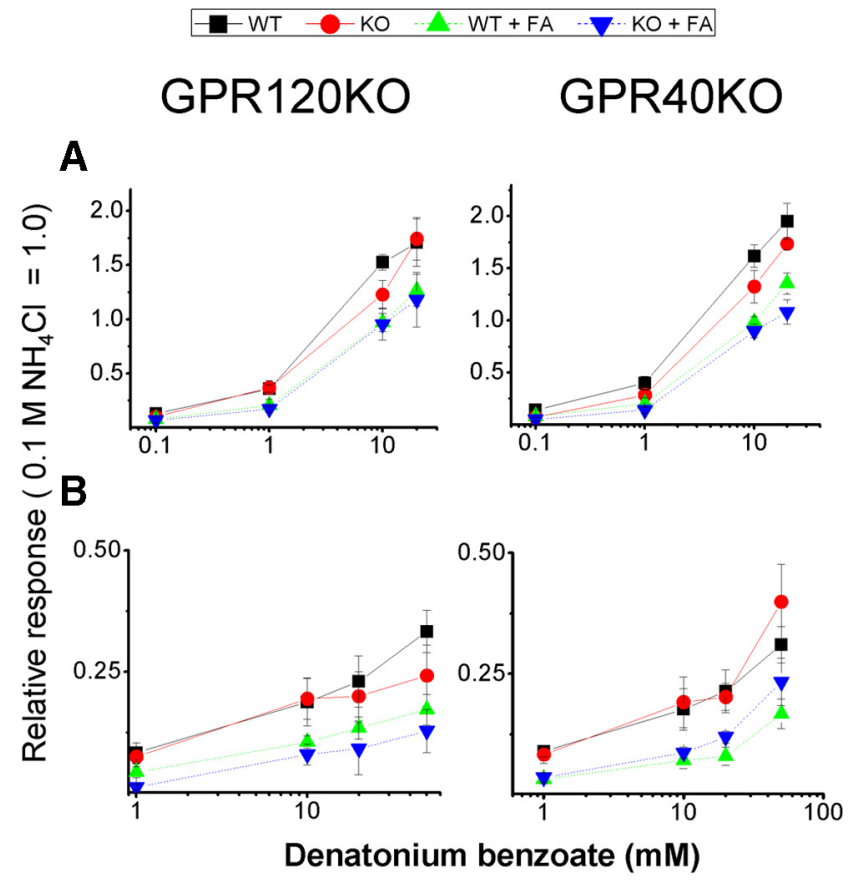

Figure 5. $\quad \boldsymbol{A}, \boldsymbol{B}$, Integrated whole nerve responses from the $\mathrm{GL}(\boldsymbol{A})$ and $\mathrm{CT}(\boldsymbol{B})$ nerves. Denatonium benzoate was tested in the absence (KO, red circles; control, black squares) or presence (KO, inverted blue triangle; control, green triangle) of a mix of $55 \mu \mathrm{m}$ linoleic acid and $33 \mu \mathrm{m}$ oleic acid. K0 groups are GPR120 K0 (left) and GPR40 K0 (right). There is no difference in responses to denatonium between $\mathrm{KO}$ and control mice. The fatty acid mix reduces the nerve response to denatonium, but this effect is GPR120 and GPR40 independent. Error bars are SEM.

the CT responses to fatty acids were unchanged in the GPR40 KO mice. By contrast, GPR120 is expressed at the front and back of the tongue and GPR120 KO mice have blunted GL and CT nerve responses to fatty acids. Our GPR120 expression data are consistent with those of (Matsumura et al., 2007), who also demonstrated expression of GPR120 in taste tissue. However, unlike Matsumura et al., we could also demonstrate GPR40 expression in the CV. This discrepancy may be related to methodological differences, since they have used PCR and we used immunohistochemistry, or to species differences as they used rats for their study.

Another protein involved in fat taste transduction is CD36. This member of the family of scavenger receptors transports fatty acids into the cytoplasm of adipocytes and myocytes (Ibrahimi and Abumrad, 2002), it is expressed in taste buds and CD36 knock-out mice have a markedly diminished preference for linoleic acid (Laugerette et al., 2005). Taste cells expressing CD36 respond to linoleic acid by increasing intracellular calcium and inositol triphosphate concentrations, SRC-kinase phosphorylation and neurotransmitter release (El Yassimi et al., 2008). The role of CD36 in fat taste signal transduction may be to bring fatty acid molecules to the actual receptor. A transporter may be required to translocate fatty acid molecules to the receptor from saliva where they may be associated with binding proteins or forming micelles, since most concentrations of fatty acids that were used here are above their critical micelle concentration (CMC). It was previously demonstrated that mouse CD36 is a coreceptor or facilitator of activation of toll-like receptors 2 and 6 by diacylglyceride (Hoebe et al., 2005) and that SNMP, the drosophila homolog of CD36 is essential for pheromone detection (Benton et al., 2007). In both cases, CD36 may act by transporting the ligand to the receptor. 
GPR40

CT nerve
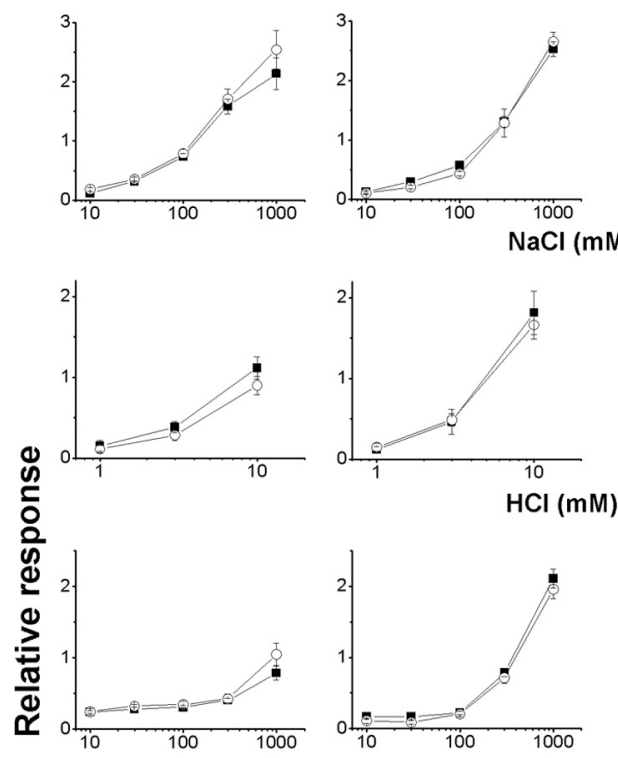

MPG (mM)
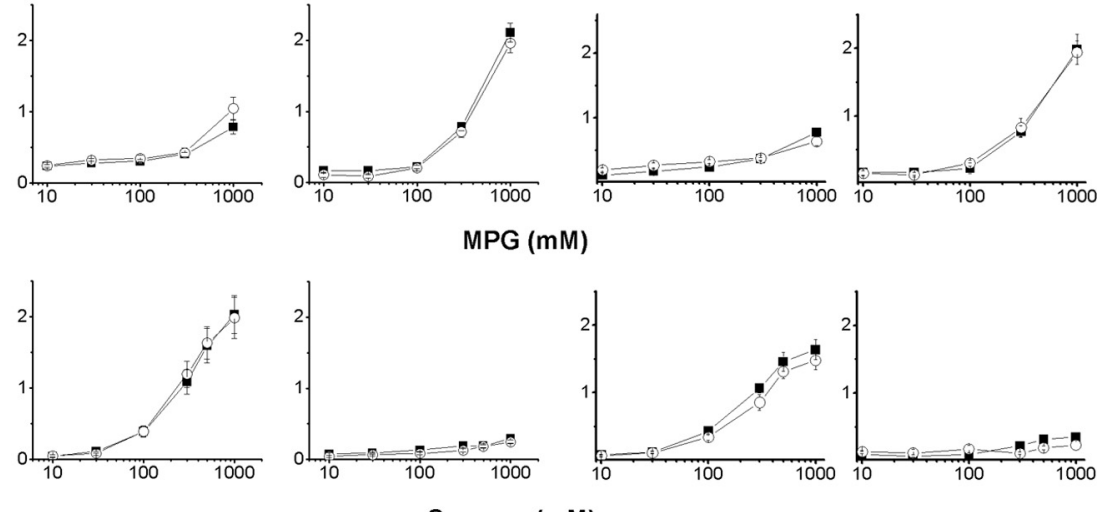

Sucrose (mM)

Figure 6. CT and GL integrated whole nerve responses of control (black squares) and GPR120 K0 or GPR40 K0 (open circles) mice to lingual application of tastants. All responses were normalized to the response to $100 \mathrm{mM} \mathrm{NH}_{4} \mathrm{Cl}$. There is no significant difference between $\mathrm{KO}$ and control in the nerve responses to $\mathrm{NaCl}, \mathrm{HCl}$, monopotassium glutamate (MPG), and sucrose. Error bars are SEM.

our data do not exclude a contribution of GPR120 and/or GPR40-dependent postingestive signals to fat preference, although the short access test shows that postingestive cues are not the only driver of preference. Flavor preference can be conditioned in rodents by intragastric infusion of lipids, and repeated exposures to linoleic acid emulsions lead to increased preference, suggesting an important role for postingestive signals in the preference for fat (Sclafani and Glendinning, 2005; Sclafani et al., 2007a). GPR120 is expressed in the gut and mediates GLP-1 and CCK release in response to fatty acids (Hirasawa et al., 2005; Tanaka et al., 2008). GPR40 is expressed in the pancreas and mediates the modulation of insulin secretion by circulating fatty acids (Itoh et al., 2003). GPR40 is also expressed in enteroendocrine cells of the intestine and mediates free fatty acid stimulation of incretin secretion (Edfalk et al., 2008). Whether GPR120 and GPR40 play a role in the postingestive preference for fat, possibly through their expression in the gut and in the pancreas will require further investigation.

We found that low concentrations of fatty acids reduce the taste nerve response of mice to denatonium, and that this modulation of the response is independent of GPR40 or GPR120. Fatty acids have previously been shown to modulate other taste qualities in rats and in humans. Pittman et al. (2006) found that $88 \mu \mathrm{M}$ oleic acid, linoleic acid or oleic-linoleic

Other candidate fat taste receptors are delayed rectifying potassium channels (DRKs), which are inhibited by polyunsaturated fatty acids in vitro (Gilbertson et al., 1997). These channels may contribute to the fat taste response independently of GPCR signaling, may underlie the alteration of bitter taste by fatty acids, or alternatively, they may be part of the transduction cascade initiated by activation of GPR40, or GPR120. In pancreatic cells, linoleic acid reduces a voltage-dependent potassium current and this effect is in part GPR40-dependent (Feng et al., 2006).

The signaling pathways downstream of GPR40 and GPR120 remain to be determined. GPR40 may couple to a G-protein $\alpha$ subunit from the $\mathrm{G} \alpha \mathrm{q}$ or $\mathrm{G} \alpha \mathrm{i}$ family (Briscoe et al., 2003; Itoh et al., 2003). GPR120 and GPR40 are unlikely to couple to gustducin because $\alpha$-gustducin knock-out mice have a normal response to soybean oil (Sclafani et al., 2007b). Trpm5, a key signaling molecule for sweet, bitter and umami tastes plays a role in the transduction of fat taste signals since Trpm $5 \mathrm{KO}$ mice showed no preference for soybean oil emulsions (supplemental Fig. S4, available at www.jneurosci.org as supplemental material) (Sclafani et al., 2007b).

Preference for food-borne molecules may result from many cues, including gustatory, olfactory, trigeminal and postingestive signals, and this is particularly true for fat. Expression of GPR40 and GPR120 in taste cells, and diminished taste nerve responses in the knock-out mice show that these two GPCRs contribute to preference for fatty acids through the gustatory system. However, acid mix increase the licking responses of rats to sucrose and glucose, and diminish the responses to quinine, $\mathrm{NaCl}$ and citric acid. Human studies showed higher thresholds for sodium chloride, citric acid, and caffeine solutions and lower intensity of high concentrations of caffeine in the presence than in the absence of $1 \%$ linoleic acid (Mattes, 2007). Our results are consistent with those obtained with humans in that they showed decreased responses to a bitter compound in the presence of fatty acids. The molecular mechanism by which this modulation occurs is unclear although we have shown it is independent of GPR40 and GPR120. It is unlikely to be due to direct molecular interactions between the fatty acids and denatonium, because the concentration of fatty acids (micromolar) is much lower than that of denatonium (millimolar). Possible mechanisms include direct inhibition of the response of the denatonium receptors, interaction with potassium channels, or modification of the membrane properties of the taste receptor cells.

The coding mechanism for fat taste at the periphery appears to be different from sweet, bitter and umami tastes where dedicated subsets of distinct cells encode the taste modalities and tastant selectivity is determined by the nature of the receptors (Zhang et al., 2003; Zhao et al., 2003). For fat taste at least two GPCRs play a role and they are expressed in a large subset of taste bud cells, namely the type I cells for GPR40 and the type II cells for GPR120. Tastant selectivity in the case of fat may be determined by cells that coexpress GPR40 or GPR120 with CD36 and specific down- 
stream signaling molecules such as DRKs. Alternatively, it is possible that all cells that express GPR40 or GPR120 are activated by fatty acids, and it is the pattern of activation of taste bud cells or the nature of the neurotransmitter that encodes the signal of fat taste.

In conclusion, based on the results of immunohistochemistry, preference tests and nerve recordings, we found that GPR40 and GPR120 mediate taste preference for fat. Better understanding of the receptors involved in fat taste will lead to the development of noncaloric molecules with fat taste and more palatable fat replacers, which will help the fight against the obesity epidemic.

\section{References}

Benton R, Vannice KS, Vosshall LB (2007) An essential role for a CD36-related receptor in pheromone detection in Drosophila. Nature 450:289-293.

Bezençon C, le Coutre J, Damak S (2006) Taste-signaling proteins are coexpressed in solitary intestinal epithelial cells. Chem Senses 32:41-49.

Briscoe CP, Tadayyon M, Andrews JL, Benson WG, Chambers JK, Eilert MM, Ellis C, Elshourbagy NA, Goetz AS, Minnick DT, Murdock PR, Sauls HR Jr, Shabon U, Spinage LD, Strum JC, Szekeres PG, Tan KB, Way JM, Ignar DM, Wilson S, et al. (2003) The orphan G-protein-coupled receptor GPR40 is activated by medium and long chain fatty acids. J Biol Chem 278:11303-11311.

Chale-Rush A, Burgess JR, Mattes RD (2007) Evidence for human orosensory (taste?) sensitivity to free fatty acids. Chem Senses 32:423-431.

Edfalk S, Steneberg P, Edlund H (2008) Gpr40 is expressed in enteroendocrine cells and mediates free fatty acid stimulation of incretin secretion. Diabetes 57:2280-2287.

El Yassimi A, Hichami A, Besnard P, Khan NA (2008) Linoleic acid induces calcium signaling, Src kinase phosphorylation, and neurotransmitter release in mouse CD36-positive gustatory cells. J Biol Chem 283:1294912959.

Feng DD, Luo Z, Roh SG, Hernandez M, Tawadros N, Keating DJ, Chen C (2006) Reduction in voltage-gated $\mathrm{K}+$ currents in primary cultured rat pancreatic beta-cells by linoleic acids. Endocrinology 147:674-682.

Fukuwatari T, Shibata K, Iguchi K, Saeki T, Iwata A, Tani K, Sugimoto E, Fushiki T (2003) Role of gustation in the recognition of oleate and triolein in anosmic rats. Physiol Behav 78:579-583.

Gilbertson TA, Fontenot DT, Liu L, Zhang H, Monroe WT (1997) Fatty acid modulation of $\mathrm{K}+$ channels in taste receptor cells: gustatory cues for dietary fat. Am J Physiol 272:C1203-C1210.

Hirasawa A, Tsumaya K, Awaji T, Katsuma S, Adachi T, Yamada M, Sugimoto Y, Miyazaki S, Tsujimoto G (2005) Free fatty acids regulate gut incretin glucagon-like peptide-1 secretion through GPR120. Nat Med 11:90-94.

Hoebe K, Georgel P, Rutschmann S, Du X, Mudd S, Crozat K, Sovath S, Shamel L, Hartung T, Zahringer U, Beutler B (2005) CD36 is a sensor of diacylglycerides. Nature 433:523-527.

Ibrahimi A, Abumrad NA (2002) Role of CD36 in membrane transport of long-chain fatty acids. Curr Opin Clin Nutr Metab Care 5:139-145.

Itoh Y, Kawamata Y, Harada M, Kobayashi M, Fujii R, Fukusumi S, Ogi K, Hosoya M, Tanaka Y, Uejima H, Tanaka H, Maruyama M, Satoh R, Okubo S, Kizawa H, Komatsu H, Matsumura F, Noguchi Y, Shinohara T, Hinuma S, et al (2003) Free fatty acids regulate insulin secretion from pancreatic beta cells through GPR40. Nature 422:173-176.

Kawai K, Sugimoto K, Nakashima K, Miura H, Ninomiya Y (2000) Leptin as a modulator of sweet taste sensitivities in mice. Proc Natl Acad Sci U S A 97:11044-11049.

Kawai T, Fushiki T (2003) Importance of lipolysis in oral cavity for orosensory detection of fat. Am J Physiol Regul Integr Comp Physiol 285:R447-R454.
Kotarsky K, Nilsson NE, Flodgren E, Owman C, Olde B (2003) A human cell surface receptor activated by free fatty acids and thiazolidinedione drugs. Biochem Biophys Res Commun 301:406-410.

Laugerette F, Passilly-Degrace P, Patris B, Niot I, Febbraio M, Montmayeur JP, Besnard P (2005) CD36 involvement in orosensory detection of dietary lipids, spontaneous fat preference, and digestive secretions. J Clin Invest 115:3177-3184.

Lawton DM, Furness DN, Lindemann B, Hackney CM (2000) Localization of the glutamate-aspartate transporter, GLAST, in rat taste buds. Eur J Neurosci 12:3163-3171.

Lindemann B (2001) Receptors and transduction in taste. Nature 413:219-225.

Matsumura S, Mizushige T, Yoneda T, Iwanaga T, Tsuzuki S, Inoue K, Fushiki T (2007) GPR expression in the rat taste bud relating to fatty acid sensing. Biomed Res 28:49-55.

Matsumura S, Eguchi A, Mizushige T, Kitabayashi N, Tsuzuki S, Inoue K, Fushiki T (2009) Colocalization of GPR120 with phospholipase-Cbeta2 and alpha-gustducin in the taste bud cells in mice. Neurosci Lett 450:186-190

Mattes RD (2007) Effects of linoleic acid on sweet, sour, salty, and bitter taste thresholds and intensity ratings of adults. Am J Physiol Gastrointest Liver Physiol 292:G1243-G1248.

Ninomiya Y (1998) Reinnervation of cross-regenerated gustatory nerve fibers into amiloride-sensitive and amiloride-insensitive taste receptor cells. Proc Natl Acad Sci U S A 95:5347-5350.

Pittman DW, Labban CE, Anderson AA, O'connor HE (2006) Linoleic and oleic acids alter the licking responses to sweet, salt, sour, and bitter tastants in rats. Chem Senses 31:835-843.

Pittman D, Crawley ME, Corbin CH, Smith KR (2007) Chorda tympani nerve transection impairs the gustatory detection of free fatty acids in male and female rats. Brain Res 1151:74-83.

Sclafani A, Glendinning JI (2005) Sugar and fat conditioned flavor preferences in C57BL/6J and 129 mice: oral and postoral interactions. Am J Physiol Regul Integr Comp Physiol 289:R712-R720.

Sclafani A, Ackroff K, Abumrad NA (2007a) CD36 gene deletion reduces fat preference and intake but not postoral fat conditioning in mice. Am J Physiol Regul Integr Comp Physiol 293:R1823-R1832.

Sclafani A, Zukerman S, Glendinning JI, Margolskee RF (2007b) Fat and carbohydrate preferences in mice: the contribution of alpha-gustducin and Trpm5 taste-signaling proteins. Am J Physiol Regul Integr Comp Physiol 293:R1504-R1513.

Stratford JM, Curtis KS, Contreras RJ (2006) Chorda tympani nerve transection alters linoleic acid taste discrimination by male and female rats. Physiol Behav 89:311-319.

Takeda M, Sawano S, Imaizumi M, Fushiki T (2001) Preference for corn oil in olfactory-blocked mice in the conditioned place preference test and the two-bottle choice test. Life Sci 69:847-854.

Tanaka T, Katsuma S, Adachi T, Koshimizu TA, Hirasawa A, Tsujimoto G (2008) Free fatty acids induce cholecystokinin secretion through GPR120. Naunyn Schmiedebergs Arch Pharmacol 377:523-527.

Wong GT, Gannon KS, Margolskee RF (1996) Transduction of bitter and sweet taste by gustducin. Nature 381:796-800.

Yang R, Crowley HH, Rock ME, Kinnamon JC (2000) Taste cells with synapses in rat circumvallate papillae display SNAP-25-like immunoreactivity. J Comp Neurol 424:205-215.

Zhang Y, Hoon MA, Chandrashekar J, Mueller KL, Cook B, Wu D, Zuker CS, Ryba NJ (2003) Coding of sweet, bitter, and umami tastes: different receptor cells sharing similar signaling pathways. Cell 112:293-301.

Zhao GQ, Zhang Y, Hoon MA, Chandrashekar J, Erlenbach I, Ryba NJ, Zuker CS (2003) The receptors for mammalian sweet and umami taste. Cell 115:255-266. 